\title{
FITOSSANIDADE
}

\section{EFEITO DE INSETICIDAS NA SEMEADURA SOBRE PRAGAS INICIAIS E PRODUTIVIDADE DE MILHO SAFRINHA EM PLANTIO DIRETO(1)}

\author{
GESSI CECCON ${ }^{(2)}$; ADALTON RAGA ${ }^{(3)}$; AILDSON PEREIRA DUARTE ${ }^{(2)}$; ROMILDO CÁSSIO SILOTO ${ }^{(3)}$
}

\begin{abstract}
RESUMO
Considerando o aumento do complexo de pragas em lavouras de milho safrinha, foram desenvolvidos dois experimentos (A e B) no município de Cândido Mota (SP). O objetivo foi avaliar o efeito de inseticidas sobre pragas de solo (percevejos-castanhos e corós), lagarta-do-cartucho na fase inicial da cultura e desenvolvimento das plantas. Os inseticidas utilizados na semeadura foram: thiamethoxam (Cruiser 700 WS), carbofuran (Furazin 310 TS), imidacloprid (Gaucho FS), imidacloprid (Gaucho FS) + carbofuran (Furazin $310 \mathrm{TS}$ ), fipronil (Regent $800 \mathrm{WG}$ ) e thiodicarb (Semevin $350 \mathrm{RPA}$ ), nas doses recomendadas de cada produto, e a testemunha sem inseticida. As pragas de solo foram avaliadas aos 14 e 28 dias após a emergência das plantas (DAE), no experimento A, e aos 7 e 21 DAE, no experimento B. Os parâmetros agronômicos foram avaliados aos 14 e 28 DAE, juntamente com o ataque por Spodoptera frugiperda, e também por ocasião da colheita dos grãos. Os inseticidas fipronil e carbofuran destacaramse no controle do percevejo-castanho Scaptocoris castanea e o fipronil sobressaiu no controle dos corós (Phyllophaga spp). Os inseticidas carbofuran e thiodicarb reduziram o número de plantas danificadas pela lagarta-do-cartucho Spodoptera frugiperda. O controle químico do complexo de pragas do solo e da lagarta-do-cartucho proporcionou aumentos significativos da produtividade de grãos de milho apenas na área A, onde o número de corós era maior.
\end{abstract}

Palavras-chave: Manejo de pragas, Scaptocoris castanea, Phyllophaga spp, Spodoptera frugiperda, Zea mays.

\section{ABSTRACT \\ EFFECT OF INSETICIDES AT SOWING ON SEEDLING PESTS AND YIELD OFF-SEASON MAIZE CROP UNDER NO-TILLAGE SYSTEM}

Due to an increasing pest diversity in maize crop during the off-season, two autumn-winter experiments were conducted in the Medium Paranapanema region, State of São Paulo, Brazil, designated as Fields A and B, both in Cândido Mota County. The aim of the experiments were to evaluate the effect of insecticides on the control of pests occurring in the initial plant development. Treatments were the recommended dosage of the insecticides thiamethoxam (Cruiser $700 \mathrm{WS}$ ), carbofuran (Furazin 310 TS), imidacloprid (Gaucho FS), imidacloprid (Gaucho FS) + carbofuran (Furazin 310 TS), fipronil (Regent 800

( $\left.{ }^{1}\right)$ Recebido para publicação em 30 de abril de 2002 e aceito em 5 de abril de 2004.

$\left({ }^{2}\right)$ Convênio IAC/Fundag/Coopermota, Pólo de Desenvolvimento Tecnológico dos Agronegócios do Médio Paranapanema, Caixa Postal 263, 19805-000, Assis (SP). E-mail:aildson@femanet.com.br

( $\left.{ }^{3}\right)$ Centro de Pesquisa e Desenvolvimento de Sanidade Vegetal/Instituto Biológico (IB), Caixa Postal 70, 13001-970 Campinas (SP). E-mail: adalton@biologico.sp.gov.br 
WG), thiodicarb (Semevin $350 \mathrm{RPA}$ ); and the control (without insecticide). The soil insects (burrowing bugs and grubs) populations were evaluated at $14^{\text {th }}$ and $28^{\text {th }}$ days after plant emergency (DAE), in Field $\mathbf{A}$, and at $7^{\text {th }}$ and $21^{\text {th }}$ DAE, in the Field B. Spodoptera frugiperda incidence and corn plant parameters were evaluated at $14^{\text {th }}$ and $28^{\text {th }}$ DAE. Fipronil and carbofuran performed best on the control of Scaptocoris castanea. Fipronil alone provided also the best control for grubs (Phyllophaga spp.). Carbofuran and thiodicarb reduced damages from fall armyworm. The chemical control of corn pests in the initial stage of the crop enhanced grain productivity only in the field A were the number of grubs in the soil was highest.

Key words: Pest management, Scaptocoris castanea, Phyllophaga spp, Spodoptera frugiperda, Zea mays.

\section{INTRODUÇÃO}

Na cultura de milho safrinha, o aumento de ocorrência de pragas subterrâneas, de pragas iniciais da cultura e de insetos vetores de fitopatógenos está associado a fatores como monocultura da sucessão soja-milho safrinha, semeadura em época marginal e aumento de lavouras em plantio direto. Entre as medidas de manejo, deve-se priorizar a rotação de culturas e a semeadura na época indicada, a fim de viabilizar a utilização de insumos, importantes componentes no custo de produção (DUARTE, 2001). Uma das alternativas que visam minimizar a ação das pragas e evitar perdas de produtividade das culturas é a utilização de inseticidas via tratamento de sementes (Cruz et al., 1999).

Dentre as principais pragas de solo que podem ocorrer na cultura do milho safrinha destacam-se adultos e ninfas de percevejos-castanhos (Hemiptera: Cydnidae) e larvas de corós (Coleoptera: Scarabaeoidea).

Os percevejos-castanhos possuem hábitos subterrâneos e podem ser encontrados em todas as épocas do ano em diferentes profundidades do solo (CRUZ e BIANCO, 2001). No Brasil, esses insetos causam prejuízos em diversas culturas de importância econômica, principalmente em soja, milho, algodão e pastagens (Siloto e RAGA, 1998), como também em plantas invasoras (RAMiro et al., 1997).

No Estado de São Paulo, a espécie Scaptocoris castanea tem sido observada com maior freqüência e intensidade em soja, milho e algodão, apresentando ataque nas raízes das plantas, no sentido da linha de semeadura, nem sempre formando reboleiras típicas (Raga et al. 2000). Segundo Siloto e Raga (1998), as plantas atacadas têm suas raízes sugadas por ninfas e adultos, tornando-se raquíticas, com desenvolvimento reduzido e afetando diretamente a produção. Em ataques severos, nos estádios iniciais da cultura, pode haver necessidade de replantio.

Hábito subterrâneo e deslocamento no perfil do solo são características desses insetos que constituem fatores limitantes no seu manejo e a aplicação de produtos, via tratamento de sementes, tem sido uma alternativa de controle (ÁviLA e GoMEs, 2001; RAGA et al., 2000; SiLото et al., 2001). Os percevejos-castanhos deslocam-se no perfil do solo, aprofundando-se nas épocas mais secas e voltando à superfície no período chuvoso. Esse fato pode estar associado a um gradiente ótimo de umidade e ser influenciado pela ocorrência de chuvas, semelhante ao que descreveram Medeiros e SALES Junior (2000), que observaram correlação positiva entre o volume de chuvas e o número de ninfas e adultos de Atarsocoris brachiariae, coletados principalmente na faixa de $0,20 \mathrm{~m}$ de profundidade. Siloto et al. (2001), estudando a incidência de $S$. castanea na camada de zero a $50 \mathrm{~cm}$, observaram picos populacionais da praga, de 30 a 60 dias após os meses de maior precipitação pluvial.

Os corós constituem-se em importantes pragas das culturas anuais no Brasil. Os gêneros mais comuns são Phyllophaga, Cyclocephala, Diloboderus e Liogenys e existem poucas informações sobre a quantificação de seus danos em milho (GASSEN, 1999). O ataque em plantas de milho, pela alimentação das larvas, provocam enfraquecimento do sistema radicular e conseqüente tombamento e morte das plântulas (CRUZ e BIANCO, 2001). Os gêneros Diloboderus e Phyllophaga têm sido relatados em cereais de inverno no Rio Grande do Sul (SAlvadori, 1997) e este último também em milho safrinha na Região Centro-Oeste do Brasil (OLIVEIRA et al., 1999). Em Mato Grosso do Sul, a ocorrência do gênero Liogenys foi constatada na cultura do milho por Ávila e Rumiatto (1997). No oeste do Paraná, a espécie Phyllophaga cuyabana foi relatada em soja por Oliveira et al. (1996). Os adultos do gênero Phyllophaga ocorrem em revoadas nos meses de novembro e dezembro, e as larvas a partir de dezembro até setembro, deslocando-se sob a superfície do solo em direção à base das plantas, das quais consomem as raízes até completar a fase larval ou causar a morte da planta hospedeira (GASSEN, 1996).

No México, as larvas de Phyllophaga spp. consomem raízes de diversas espécies de gramíneas e são pragas severas em milho (MORÓN, 1986), estimandose perdas de 0,4 a 1,3 toneladas de milho por hectare/ ano (Villalobos, 1988). 
A lagarta-do-cartucho Spodoptera frugiperda é a principal praga da cultura do milho devido à sua ocorrência generalizada e ao seu potencial de ataque em todas as fases de desenvolvimento da planta, provocando quedas significativas no rendimento (CRUZ e TURPIN, 1982). Quando o ataque ocorre na fase inicial da cultura, essas perdas são ainda mais significativas devido à morte das plântulas e à diminuição do número de plantas por unidade de área. O controle com inseticidas via pulverização torna-se pouco efetivo em função da reduzida área foliar das plântulas nessa fase, dificultando a retenção do produto nas folhas e diminuindo o seu poder residual. A utilização de produtos sistêmicos via tratamento de sementes, nesse caso, tem-se constituído em alternativa viável (Cruz e Bianco, 2001).

O presente trabalho foi desenvolvido com o objetivo de avaliar o efeito de inseticidas sobre pragas de solo (percevejos-castanhos e corós), a lagarta-do-cartucho na fase inicial da cultura e o desenvolvimento das plantas de milho.

\section{MATERIAL E MÉTODOS}

Foram desenvolvidos dois experimentos, ambos no município de Cândido Mota (SP), em lavouras de milho safrinha, sob sistema de plantio direto em Latossolo Vermelho eutroférrico, com reconhecido histórico de ataque de pragas de solo e da lagarta-do-cartucho na fase inicial da cultura.
Experimento A. Instalado no Sítio Cinco Irmãos, utilizou-se o híbrido Tork, com semeadura em $2 / 3 / 2001$ e emergência em 8/3/2001. A adubação foi realizada apenas na semeadura, com $150 \mathrm{~kg} \cdot \mathrm{ha}^{-1}$ da fórmula NPK 15-15-15.

Experimento B. Instalado no Sítio Santa Luzia, com utilização do híbrido Exceler, semeado em $3 / 3 / 2001$ e com emergência em 8/3/2001. Na semeadura, empregou-se $145 \mathrm{~kg} \cdot \mathrm{ha}^{-1}$ da fórmula NPK 05-25-25 e em cobertura, $20 \mathrm{~kg} \cdot \mathrm{ha}^{-1}$ de $\mathrm{N}$ na forma de uréia.

O registro de chuvas foi obtido na estação meteorológica automatizada da Cooperativa Coopermota, eqüidistante aproximadamente $5 \mathrm{~km}$ dos dois experimentos (Figura 1).

O delineamento experimental foi o de blocos ao acaso, com cinco repetições, sendo cada parcela constituída por seis linhas de $20 \mathrm{~m}$ de comprimento e $0,9 \mathrm{~m}$ entre linhas e densidade inicial de 50.000 sementes por hectare. As avaliações foram realizadas nas duas linhas centrais de cada parcela.

Os tratamentos consistiram dos inseticidas thiamethoxam, carbofuran, imidacloprid, imidacloprid + carbofuran, fipronil e thiodicarb, além da testemunha sem inseticida (Tabela 1).

O tratamento com o inseticida fipronil foi aplicado via pulverização em jato dirigido na linha de semeadura, com bico leque e 200 L.ha $^{-1}$ de calda. Os demais inseticidas foram aplicados via tratamento de sementes.

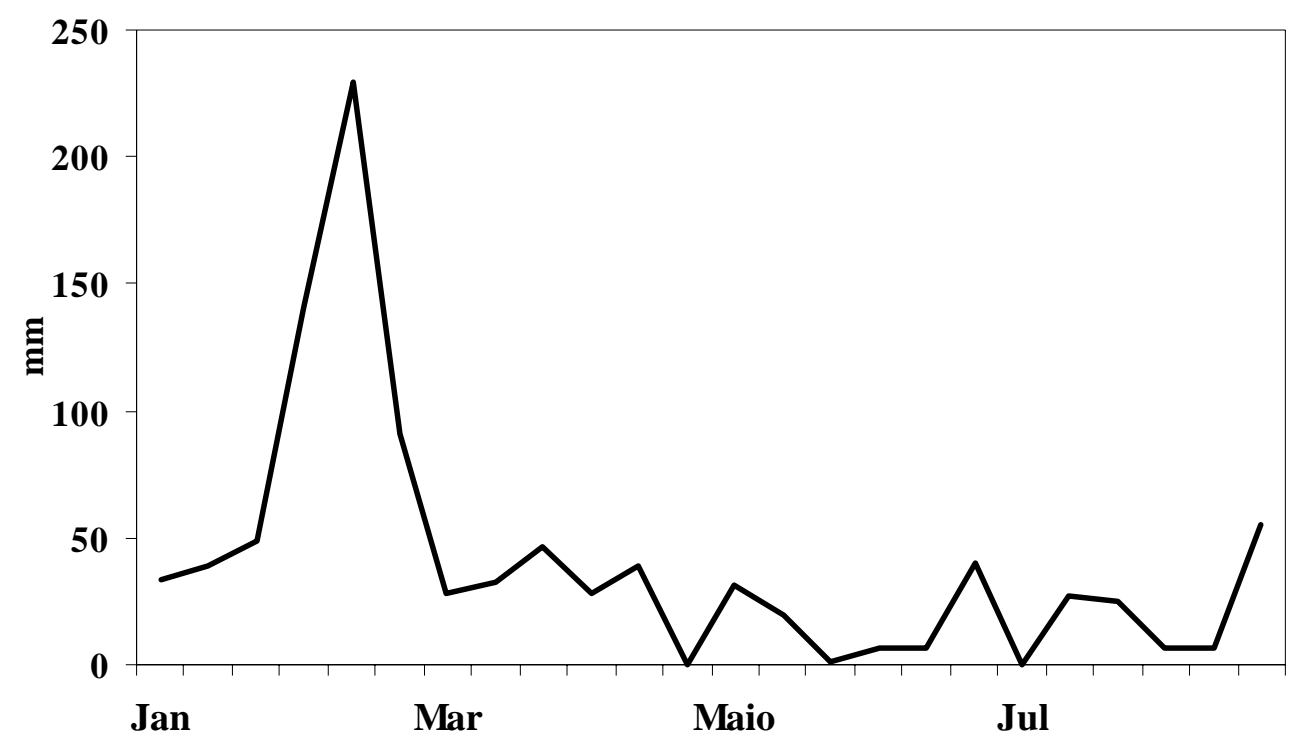

Figura 1. Precipitação pluvial decendial registrada na estação meteorológica automatizada da Cooperativa Coopermota, em Cândido Mota (SP), 2001. 
Tabela 1. Produtos utilizados para controle de insetos no milho safrinha em plantio direto no município de Cândido Mota, em 2001

\begin{tabular}{|c|c|c|c|}
\hline \multirow{2}{*}{ Tratamento } & \multirow{2}{*}{ Ingrediente ativo } & \multicolumn{2}{|c|}{ Dose utilizada } \\
\hline & & Ingrediente ativo & Produto comercial \\
\hline Cruiser $700 \mathrm{WS}^{\circledR}$ & thiamethoxam & $210 \mathrm{~g} / 100 \mathrm{~kg}$ semente & $300 \mathrm{ml} / 100 \mathrm{~kg}$ semente \\
\hline Furazin 310 TS $^{\circledR}$ & carbofuran & $620 \mathrm{~g} / 100 \mathrm{~kg}$ semente & $2,0 \mathrm{~L} / 100 \mathrm{~kg}$ semente \\
\hline Gaucho FS ${ }^{\circledR(1)}$ & imidacloprid & $210 \mathrm{~g} / 100 \mathrm{~kg}$ semente & $350 \mathrm{ml} / 100 \mathrm{~kg}$ semente \\
\hline Gaucho $^{\circledR}+$ Furazin $^{\circledR(2)}$ & imidacloprid+ carbofuran & $105 \mathrm{~g}+350 \mathrm{~g} / 100 \mathrm{~kg}$ semente & $175 \mathrm{~m}+500 \mathrm{ml} / 100 \mathrm{~kg}$ semente \\
\hline Regent $800^{\circledR} \mathrm{WG}$ & fipronil & $64 \mathrm{~g} / \mathrm{ha}$ & $80 \mathrm{~g} / \mathrm{ha}$ \\
\hline Semevin $350^{\circledR} \mathrm{RPA}$ & thiodicarb & $700 \mathrm{~g} / 100 \mathrm{~kg}$ semente & $2,0 \mathrm{~L} / 100 \mathrm{~kg}$ semente \\
\hline
\end{tabular}

$\left({ }^{1}\right)$ Utilizado apenas no experimento B; ${ }^{(2)}$ Utilizado apenas no experimento A.

Aos 16 dias após a emergência das plantas (DAE), foi realizada uma pulverização com inseticida Decis $25 \mathrm{CE}^{\circledR}$ (deltamethrin), nos dois experimentos, na dose de $200 \mathrm{~mL} \cdot \mathrm{ha}^{-1}$ e 200 L.ha $^{-1} \mathrm{de}$ calda, com pulverizador tratorizado visando ao controle de $S$. frugiperda.

O efeito dos tratamentos sobre percevejoscastanhos e corós foi avaliado aos 14 e 28 DAE no experimento $\mathbf{A}$ e aos 7 e 21 DAE no experimento $\mathbf{B}$. Foram realizadas duas amostragens por parcela, sendo cada uma constituída de solo retirado junto à linha de plantio em $1 \mathrm{~m}$ de comprimento e $0,2 \mathrm{~m}$ de largura e profundidade. $\mathrm{O}$ solo foi peneirado e os insetos coletados e contados, sendo consideradas as ninfas e os adultos para percevejos-castanhos e as larvas para corós. Os insetos foram armazenados em álcool 70\% para identificação no Laboratório de Entomologia Econômica do Instituto Biológico, em Campinas (SP). O valor de cada parcela foi obtido calculando-se a média das duas amostragens.

O efeito sobre a lagarta-do-cartucho foi avaliado aos 14 DAE e 28 DAE nos dois experimentos. Foram realizadas duas amostragens por parcela; em cada amostragem foram avaliadas as plantas presentes em $1 \mathrm{~m}$ de linha, considerando-se presença-ausência de danos no cartucho e calculado o índice de plantas danificadas (IPD $=100 \times \mathrm{n} .{ }^{\circ}$ de plantas danificadas/total de plantas avaliadas). O valor de cada parcela também foi obtido calculandose a média das duas amostragens.

Aos 14 e 28 DAE foram avaliados os seguintes parâmetros agronômicos: população, uniformidade de crescimento de plantas e massa seca da parte aérea. Os parâmetros foram calculados com base no número de plantas coletadas em $5 \mathrm{~m}$ de linha por par- cela. Calculou-se a uniformidade de crescimento de plantas segundo o percentual de plantas raquíticas (com altura menor que a média do experimento) em relação ao total de plantas avaliadas. Para obtenção da massa seca da parte aérea, o material coletado foi seco em estufa a $60{ }^{\circ} \mathrm{C}$.

Na colheita foram avaliados os parâmetros de altura e população de plantas, massa seca da parte aérea sem espiga (palha), produtividade, massa de grãos por espiga e massa de mil grãos.

O dados foram submetidos à análise de variância pelo teste $\mathrm{F}(\mathrm{P}<0,05)$ e as médias comparadas pelo teste de Tukey a $5 \%$ de probabilidade. Os dados originais relativos aos insetos foram transformados em $\sqrt{x+0,5}$.

\section{RESULTADOS E DISCUSSÃO}

Segundo BECKER (1967), as ninfas e os adultos de percevejos-castanhos foram identificados como $S$. castanea e com base em GASSEN (1996), as larvas de corós foram identificadas como Phyllophaga spp.

Nos dois experimentos foram encontradas mais ninfas do que adultos nas duas avaliações. No experimento $\mathbf{A}$, o número médio de percevejos-castanhos foi de 29,7 aos 14 DAE e de 13,6 aos 28 DAE (Tabela 2). No experimento B, o número médio desses insetos foi de 11,4 aos 7 DAE e de 11,6 aos 21 DAE; o número de adultos foi bastante reduzido, com média dos tratamentos inferior a dois insetos (Tabela 3).

No experimento $\mathbf{A}$, houve queda acentuada no nível populacional de $S$. castanea entre a $1 .^{\mathrm{a}}$ e a $2 .^{\mathrm{a}}$ avaliações, inclusive na testemunha, assemelhando-se 
aos resultados obtidos por SiLOTO et al. (2000) que também observaram esse fato em experimento com inseticidas para o controle de percevejos-castanhos, quando se registrou, nos 26 dias anteriores à última avaliação, precipitação pluvial de apenas $8 \mathrm{~mm}$. Os percevejos-castanhos têm grande capacidade de deslocamento no perfil do solo, provavelmente influenciado por um gradiente ótimo de umidade (SILOTo et al., 2001). Houve diminuição das chuvas no período de realização dos experimentos (Figura 1) e sua distribuição não foi uniforme, o que pode ter levado os insetos a se deslocarem para camadas mais profundas.

Houve redução significativa de $S$. castanea, em comparação à testemunha, no tratamento com fipronil $800 \mathrm{WG}$ aos $14 \mathrm{DAE}$, no experimento $\mathrm{A}$, e no trata- mento com carbofuran 310 TS aos 21 DAE, no experimento $\mathbf{B}$. Os referidos tratamentos não diferiram do thiamethoxam nos dois experimentos (Tabelas 2 e 3). No experimento $\mathbf{A}$, aos $14 \mathrm{DAE}$, o número de percevejos-castanhos (ninfas + adultos) foi significativamente menor para o tratamento com fipronil em relação aos tratamentos com carbofuran, imidacloprid + carbofuran e thiodicarb, mas não diferiu de thiamethoxam e da testemunha.

Aos 28 DAE os tratamentos não apresentaram diferença significativa entre si (Tabela 2 ). No experimento $\mathbf{B}$, houve diferença significativa entre os tratamentos aos $21 \mathrm{DAE}$; carbofuran apresentou redução da população em relação aos tratamentos com imidacloprid, fipronil e testemunha, sem diferir de thiamethoxam (Tabela 3).

Tabela 2. Número médio de insetos coletados em milho safrinha sob diferentes tratamentos com inseticidas e avaliados aos 14 e 28 dias após a emergência das plantas (DAE), em Cândido Mota (A), em 2001

\begin{tabular}{|c|c|c|c|c|}
\hline \multirow{2}{*}{ Tratamento } & \multicolumn{3}{|c|}{ N. ${ }^{\circ}$ de percevejos-castanhos } & \multirow{2}{*}{ N. ${ }^{\circ}$ de corós } \\
\hline & Ninfas & Adultos & Total & \\
\hline & & 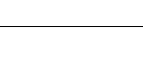 & +2 & +2 \\
\hline Thiamethoxam & $16,8^{\mathrm{ns}}$ & $8,3 \mathrm{ab}$ & $25,1 \mathrm{ab}$ & $9,7^{\mathrm{ns}}$ \\
\hline Carbofuran & 30,8 & 15,2 a & 46,0 a & 0,4 \\
\hline Imidacloprid+Carbofuran & 27,0 & 12,7 a & 39,7 a & 12,8 \\
\hline Fipronil & 5,0 & $2,2 \mathrm{~b}$ & $7,2 \mathrm{~b}$ & 6,4 \\
\hline Thiodicarb & 27,0 & $9,9 \mathrm{ab}$ & 37,6 a & 9,5 \\
\hline Testemunha & 16,8 & $5,8 \mathrm{ab}$ & $22,6 \mathrm{ab}$ & 9,4 \\
\hline Média & 0,6 & 9,0 & 29,7 & 8,0 \\
\hline C.V.(\%) & 42 & 47 & 43 & 23 \\
\hline Thiamethoxam & $9,4^{\mathrm{ns}}$ & 2,6 ns & 12,0 ns & 11,3 a \\
\hline Carbofuran & 5,8 & 1,9 & 7,7 & 12,2 a \\
\hline Imidacloprid+Carbofuran & 14,2 & 5,9 & 20,1 & $8,3 \mathrm{ab}$ \\
\hline Fipronil & 13,3 & 4,2 & 17,6 & $4,8 \quad b$ \\
\hline Thiodicarb & 10,5 & 3,9 & 14,4 & $10,0 \mathrm{ab}$ \\
\hline Testemunha & 6,1 & 3,9 & 10,0 & $8,7 \mathrm{ab}$ \\
\hline Média & 9,9 & 3,7 & 13,6 & 9,2 \\
\hline C.V.(\%) & 31 & 32 & 30 & 25 \\
\hline
\end{tabular}

Médias seguidas pela mesma letra na coluna, não diferem pelo teste de Tukey a $5 \%$; ${ }^{\text {ns }}=$ não significativo pelo teste $\mathrm{F}$ a $5 \%$. 
Tabela 3. Número médio de insetos coletados em milho safrinha sob diferentes tratamentos com inseticidas e avaliados aos 7 e 21 dias após a emergência das plantas (DAE), em Cândido Mota (B), em 2001

\begin{tabular}{|c|c|c|c|c|}
\hline \multirow{2}{*}{ Tratamento } & \multicolumn{3}{|c|}{$\mathrm{N}^{\circ}$ de percevejos-castanhos } & \multirow{2}{*}{$\mathrm{N}^{\mathrm{o}}$ de corós } \\
\hline & Ninfa & Adulto & Total & \\
\hline Thiamethoxam & 5,1 ns & 0,9 ns & $6,0 \mathrm{~ns}$ & $1,7^{\mathrm{ns}}$ \\
\hline Carbofuran & 8,2 & 1,4 & 9,6 & 3,0 \\
\hline Imidacloprid & 6,9 & 0,4 & 7,3 & 1,9 \\
\hline Fipronil & 19,7 & 1,9 & 21,6 & 1,2 \\
\hline Testemunha & 11,3 & 1,0 & 12,3 & 2,0 \\
\hline Média & 10,2 & 1,1 & 11,4 & 2,0 \\
\hline C.V.(\%) & 51 & 45 & 49 & 20 \\
\hline
\end{tabular}

\begin{tabular}{|c|c|c|c|c|}
\hline \multirow[b]{2}{*}{ Thiamethoxam } & \multicolumn{4}{|c|}{$-21 \mathrm{DAE}$} \\
\hline & $9,5 \mathrm{ab}$ & 1,1 ns & $10,6 \mathrm{ab}$ & $0,2^{\mathrm{ns}}$ \\
\hline Carbofuran & $2,9 \mathrm{~b}$ & 0,7 & $3,6 \mathrm{~b}$ & 0,6 \\
\hline Imidacloprid & 11,4 & 2,3 & 13,7 a & 0,1 \\
\hline Fipronil & 14,1 a & 0,8 & 14,9 a & 0,2 \\
\hline Testemunha & 13,2 a & 2,1 & 15,3 a & 0,3 \\
\hline Média & 10,2 & 1,4 & 11,6 & 0,3 \\
\hline C.V.(\%) & 37 & 50 & 36 & 100 \\
\hline
\end{tabular}

Médias seguidas pela mesma letra na coluna, não diferem pelo teste de Tukey a $5 \%$; ${ }^{\text {ns }}=$ não significativo pelo teste $\mathrm{F}$ a $5 \%$.

A ação dos inseticidas, por repelência, possivelmente contribuiu para evitar a presença desses insetos junto às raízes nas parcelas tratadas. Esses são fatores que podem influir na análise do efeito dos inseticidas. Corso et al. (1999), em trabalho realizado na região de Cândido Mota (SP), detectaram eficiência média superior a $30 \%$ até $30 \mathrm{DAE}$ para os produtos thiamethoxam, imidacloprid e clorpirifós (tratamento de sementes) e também para fipronil (pulverizado no sulco de plantio), considerando-se avaliações a partir de 12 DAE. RaGa e SiLoto (1999), em trabalho realizado em milho safrinha em Florínea (SP), obtiveram níveis médios de mortalidade de $95,8 \%$ e $90 \%$, respectivamente, para terbufós e fipronil. NAKANO e FLORIM (1999) concluíram que fipronil 250 FS e fipronil 800 WG mostraram maior eficiência a $70 \%$ no controle da espécie Atarsocoris brachiariae, em soja, em Jataí (GO).

O número médio de corós foi relativamente grande no experimento A $(8,0$ e 9,2 em cada avaliação) e pequeno no experimento $\mathbf{B}(2,0$ e 0,3$)$, não se observando diferenças significativas entre os tratamentos nesse último experimento. No experimento $\mathbf{A}$, aos 28 DAE, o número de corós foi menor no tratamento com fipronil em relação ao carbofuran e thiamethoxam, não diferindo de imidacloprid + carbofuran, testemunha e thiodicarb. MARTins et al. (1999), avaliando o efeito de diferentes inseticidas sobre Phyllophaga spp. em milho, concluíram que fipronil 800 WG nas três dosagens testadas, proporcionou controle com eficiência de $100 \%$. HABE et al. (2001) testaram o efeito de diferentes produtos químicos sobre Liogenys sp. em milho e obtiveram controle de $80 \%$ até 21 DAE com thiodicarb 300 SC, enquanto thiamethoxam na dose de $210 \mathrm{~g}$ i.a. promoveu maior produtividade e vigor de plantas.

O efeito dos tratamentos sobre a lagarta-docartucho foi significativo nos dois experimentos. No experimento $\mathbf{A}$, thiodicarb se destacou em relação à testemunha e fipronil. Os tratamentos com carbofuran, thiamethoxam e imidacloprid + carbofuran também foram significativamente superiores ao fipronil, sem diferir da testemunha. No experimento $\mathbf{B}$, carbofuran diferiu em relação à testemunha. Tanto thiodicarb, no experimento $\mathbf{A}$, quanto carbofuran, no $\mathbf{B}$, apresentaram índices de plantas danificadas inferiores a $20 \%$ (Figura 2). Thiodicarb é recomendado para o controle da lagarta-do-cartucho e foi aplicado exclusivamente no experimento A. CRUz (1996) obteve redução significativa da infestação de $S$. frugiperda, 
até os $10 \mathrm{DAE}$, em plantas cujas sementes foram tratadas com thiodicarb. BeLLETTINI et al. (2002) obtiveram eficiência superior a $80 \%$ até $25 \mathrm{DAE}$, com thiamethoxam $700 \mathrm{WS}$ via tratamento de sementes. Esses inseticidas retardaram o início da infestação por S. frugiperda, o que é fator positivo, pois favorece o desenvolvimento das plantas e adia o início das pulverizações.

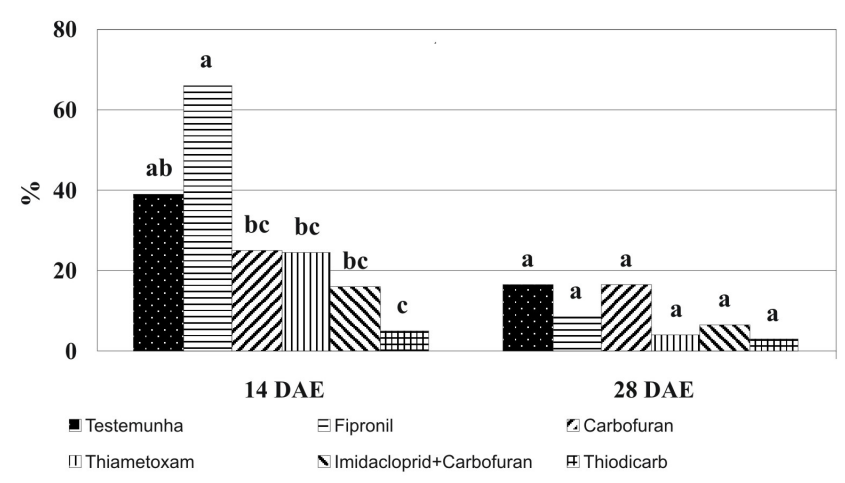

$\mathrm{Na}$ fase inicial da cultura, o controle via pulverização das plantas pode ser pouco efetivo, pois como possuem reduzida área foliar, dificulta a retenção do produto nas folhas, diminuindo o poder residual. $\mathrm{O}$ controle mais tardio pode possibilitar o estabelecimento e o incremento de inimigos naturais - importantes componentes no manejo integrado de pragas do milho.

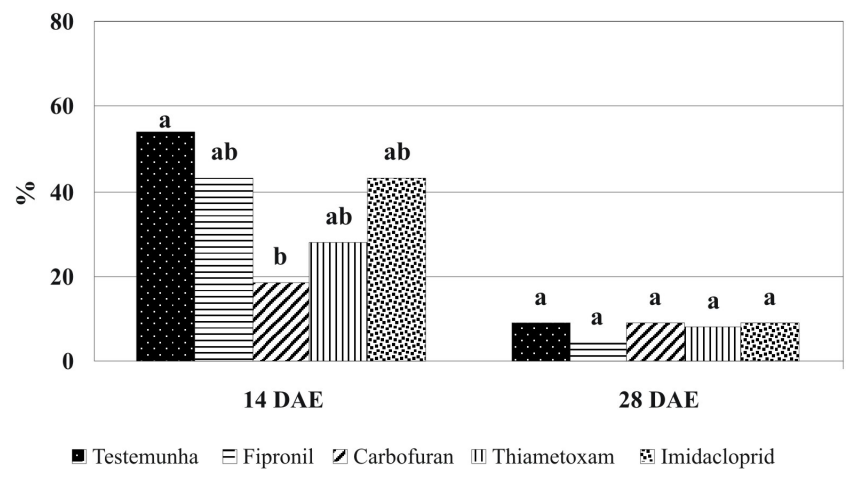

Figura 2. Incidência de $S$. frugiperda (\%) em plantas de milho safrinha, aos 14 e 28 dias após a emergência (DAE), em Cândido Mota (SP), 2001.

Quanto aos caracteres agronômicos, no experimento $\mathbf{A}$, houve diferença significativa para a população de plantas aos 28 DAE e para plantas raquíticas e massa seca, aos 14 e 28 DAE (Tabela 4). Nas avaliações aos 28 DAE, os tratamentos com imidacloprid + carbofuran e carbofuran apresentaram maiores populações de plantas do que a testemunha. Cruz (1996) obteve um estande maior que a testemunha em $19 \%$, tratando as sementes de milho com carbofuran 350 SC a 2,0 L de p.c. $/ 100 \mathrm{~kg}$ de semente. O número de plantas raquíticas foi menor em todos os tratamentos em relação à testemunha, menos com fipronil aos 28 DAE, evidenciando-se o efeito dos inseticidas na manutenção de maior proporção de plantas normais. Conseqüentemente, a massa seca da parte aérea foi significativamente maior com a aplicação de inseticidas nas duas épocas, com exceção de thiamethoxam aos 14 DAE.

No experimento $\mathbf{B}$, houve diferença para plantas raquíticas aos 14 DAE e para massa seca da parte aérea aos 14 e 28 DAE (Tabela 4). O imidacloprid destacou-se especificamente aos $14 \mathrm{DAE}$, de maneira inconsistente em relação aos $28 \mathrm{DAE}$, apresentando menor percentual de plantas raquíticas do que a testemunha e o carbofuran. Com relação à massa seca, aos $14 \mathrm{DAE}$, o carbofuran apresentou menor valor em relação aos tratamentos thiamethoxam e imidacloprid. Aos $28 \mathrm{DAE}$, os tratamentos com thiamethoxam e carbofuran apresentaram maiores valores de massa seca em relação aos demais. Carbofuran se destacou nesse experimento no controle da lagarta-do-cartucho e, especificamente, de percevejo-castanho no solo, na segunda avaliação. $\mathrm{O}$ thiamethoxam foi intermediário entre o carbofuran e os demais tratamentos para o controle do percevejo-castanho (Tabela 3).

Por ocasião da colheita de grãos do experimento $\mathbf{A}$, houve diferença significativa para os parâmetros avaliados, com exceção da altura de plantas. O tratamento com imidacloprid + carbofuran apresentou maior população de plantas do que o fipronil (Tabela 5), de maneira coerente com a superioridade da sua população de plantas aos $28 \mathrm{DAE}$ (Tabela 4). O tratamento com o fipronil foi o que apresentou maior massa de palha, sem diferir apenas de thiodicarb. Nas condições de outono-inverno, cujoo potencial produtivo é relativamente baixo, há uma compensação da produtividade com populações variando entre 33 e 44 mil plantas por hectare (DUARTE, 2001). Esse fato pode explicar porque o tratamento com fipronil, mesmo com menor população, produziu maior quantidade de palha do que o tratamento com imidacloprid + carbofuran.

A produtividade de grãos foi maior no tratamento com thiamethoxam, o qual diferiu da testemunha, mas não dos demais tratamentos (Tabela 5). Nos parâmetros de espiga, os tratamentos com thiamethoxam e fipronil foram significativamente superiores à testemunha e imidacloprid + carbofuran para massa de grãos por espiga e ao imidacloprid + carbofuran para massa de mil grãos. 
Tabela 4. População de plantas, plantas raquíticas e massa seca aos 14 e 28 dias após a emergência (DAE) em duas lavouras de milho safrinha em Cândido Mota, em 2001

\begin{tabular}{|c|c|c|c|c|c|c|}
\hline \multirow{2}{*}{ Tratamento } & \multicolumn{2}{|c|}{ População } & \multicolumn{2}{|c|}{ Plantas raquíticas } & \multicolumn{2}{|c|}{ Massa seca } \\
\hline & $14 \mathrm{DAE}$ & $28 \mathrm{DAE}$ & $14 \mathrm{DAE}$ & $28 \mathrm{DAE}$ & $14 \mathrm{DAE}$ & $28 \mathrm{DAE}$ \\
\hline
\end{tabular}

Experimento A

\begin{tabular}{|c|c|c|c|c|c|c|c|}
\hline Thiamethoxam & $37.300^{\mathrm{ns}}$ & $44.000 \mathrm{ab}$ & $19,8 \mathrm{~b}$ & $13,2 \mathrm{~b}$ & 80 & $\mathrm{~cd}$ & 1.535 \\
\hline Carbofuran & 45.300 & $46.600 \quad a$ & $11,5 \mathrm{~b}$ & $8,6 \mathrm{~b}$ & 105 & bc & 1.468 \\
\hline \multicolumn{8}{|l|}{ Imidacloprid } \\
\hline + Carbofuran & 47.500 & $48.400 \quad \mathrm{a}$ & $8,5 \mathrm{~b}$ & $8,5 \mathrm{~b}$ & 125 & $a b$ & 1.503 \\
\hline Fipronil & 40.800 & $40.800 \mathrm{ab}$ & $14,1 \mathrm{~b}$ & $21,6 \mathrm{ab}$ & 107 & $a b c$ & 1.170 \\
\hline Thiodicarb & 52.000 & $43.100 \mathrm{ab}$ & $24,9 \mathrm{~b}$ & $8,3 \mathrm{~b}$ & 149 & a & 1.546 \\
\hline Testemunha & 35.500 & $33.300 \mathrm{~b}$ & 67,3 a & 48,0 a & 55 & d & 319 \\
\hline Média & 43.100 & 42.700 & 24,4 & 18,0 & 103 & & 1.257 \\
\hline \multirow[t]{2}{*}{ C.V. $(\%)$} & 21 & 12 & 55 & 12 & 21 & & 19 \\
\hline & \multicolumn{7}{|c|}{ Experimento B } \\
\hline Thiamethoxam & $45.800^{\mathrm{ns}}$ & $48.400^{\mathrm{ns}}$ & $4,7 \mathrm{bc}$ & $2,8^{\mathrm{ns}}$ & 157 & a & 2.668 \\
\hline Carbofuran & 44.900 & 47.500 & 17,8 a & 6,6 & 116 & $\mathrm{~b}$ & 2.452 \\
\hline Imidacloprid & 46.700 & 50.200 & $1,8 \mathrm{c}$ & 8,0 & 148 & a & 1.801 \\
\hline Fipronil & 46.700 & 50.200 & $7,6 \mathrm{abc}$ & 8,8 & 140 & $a b$ & 1.852 \\
\hline Testemunha & 45.800 & 48.400 & $15,3 \mathrm{ab}$ & 12,0 & 130 & $a b$ & 1.673 \\
\hline Média & 46.000 & 48.900 & 9,4 & 7,6 & 138 & & 2.089 \\
\hline C.V.(\%) & 5 & 5 & 66 & 71 & 11 & & 14 \\
\hline
\end{tabular}

Médias seguidas pela mesma letra na coluna, não diferem pelo teste de Tukey a $5 \%$; ${ }^{\text {ns }}=$ não significativo pelo teste $\mathrm{F}$ a $5 \%$.

No experimento B, não houve diferença entre os tratamentos para população de plantas, produtividade de grãos e massa de mil grãos. Obteve-se maior altura de plantas no tratamento com fipronil, sem diferir do carbofuran. Carbofuran se destacou quanto à massa de palha, juntamente com o thiamethoxam, e à massa de grãos por espiga. O carbofuran também apresentou maior produtividade de grãos, sem diferir significativamente dos demais tratamentos.

Nas duas áreas avaliadas, a maior produção de massa seca da parte aérea não assegurou maior produtividade de grãos. Provavelmente, devido à baixa produtividade de grãos de milho e às diferenças pouco acentuadas entre os tratamentos, o número de repetições do trabalho tenha sido pequeno para diferenciar melhor os tratamentos.

No experimento B, thiamethoxam e carbofuran se destacaram quanto à produção de matéria seca da parte aérea, mas não houve diferença entre os trata- mentos para produção de grãos (Tabela 5). No experimento $\mathbf{A}$, onde havia maior número de insetos, o tratamento fipronil destacou-se quanto à massa de palha, sem diferir do thiodicarb. No entanto, o tratamento com o thiamethoxam foi o único que apresentou produtividade de grãos superior à testemunha (Tabela 5). Esses resultados de minimização dos prejuízos da produção de massa de palha e/ou grãos de milho corroboram com os obtidos por CRUz (1996), que verificou benefícios do tratamento de sementes associando thiodicarb e carbofuran sobre a produtividade do milho, possivelmente devido ao controle do complexo de pragas. SALVADORI (2001a) obteve rendimento de grãos de trigo superior à testemunha de $8,4 \%$ e $6,5 \%$, respectivamente, para thiamethoxam e fipronil, via tratamento de sementes, em área com corós.

Esse mesmo autor (SALVADORI, 2001b), porém, não registrou diferença na produtividade para fipronil ao realizar tratamento via pulverização no sulco de semeadura. 
Tabela 5. Parâmetros agronômicos na colheita do milho safrinha submetido a diferentes inseticidas aplicados na semeadura em dois experimentos em Cândido Mota, em 2001

\begin{tabular}{lllllll}
\hline Tratamentos & \multicolumn{3}{c}{ Parâmetros de plantas } & & Produtividade & \multicolumn{2}{c}{ Parâmetros de Espiga } \\
\cline { 2 - 3 } & Altura & População & Palha & Grãos & $\begin{array}{c}\text { Massa de } \\
\text { grãos / espiga }\end{array}$ & $\begin{array}{l}\text { Massa de } \\
\text { mil grãos }\end{array}$ \\
\hline
\end{tabular}

\begin{tabular}{|c|c|c|c|c|c|c|}
\hline \multirow[b]{3}{*}{ Thiamethoxam } & $\mathrm{m}$ & \multirow[t]{2}{*}{ Plantas.ha $^{-1}$} & \multirow{2}{*}{\multicolumn{2}{|c|}{$\begin{array}{c}\mathrm{kg} \cdot \mathrm{ha}^{-1} \\
\text { Experimento A }\end{array}$}} & \multirow[t]{2}{*}{ 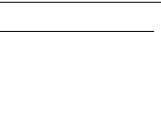 } & \multirow[t]{2}{*}{$\longrightarrow$} \\
\hline & & & & & & \\
\hline & 1,49 ns & $37.778 \mathrm{ab}$ & $4.973 \mathrm{bc}$ & 5.664 a & 151 a & $268 \mathrm{a}$ \\
\hline Carbofuran & 1,34 & $41.333 \mathrm{ab}$ & $4.054 \mathrm{c}$ & $5.347 \mathrm{ab}$ & $130 \mathrm{ab}$ & $250 \mathrm{ab}$ \\
\hline Imidacloprid+Carbofuran & 1,50 & 46.444 a & $4.314 \mathrm{bc}$ & $5.334 \mathrm{ab}$ & $114 \mathrm{~b}$ & $242 \mathrm{~b}$ \\
\hline Fipronil & 1,53 & $35.778 \mathrm{~b}$ & 7.520 a & $5.343 \mathrm{ab}$ & $147 \mathrm{a}$ & 269 a \\
\hline Thiodicarb & 2,07 & $42.000 \mathrm{ab}$ & $6.103 \mathrm{ab}$ & $5.379 \mathrm{ab}$ & $126 \mathrm{ab}$ & $251 \mathrm{ab}$ \\
\hline Testemunha & 1,16 & $37.778 \mathrm{ab}$ & $4.178 \mathrm{bc}$ & $4.224 \mathrm{~b}$ & $112 \mathrm{~b}$ & $254 \mathrm{ab}$ \\
\hline Média & 1,51 & 40.185 & 5.190 & 5.332 & 130 & 255 \\
\hline \multirow[t]{2}{*}{ C.V.(\%) } & 36 & 12 & 19 & 11 & 10 & 4 \\
\hline & \multicolumn{6}{|c|}{ Experimento B } \\
\hline Thiamethoxam & $1,27 \mathrm{~d}$ & 43.800 ns & $4.989 \mathrm{~b}$ & $4.361 \mathrm{~ns}$ & $97 \mathrm{~b}$ & $271 \mathrm{~ns}$ \\
\hline Carbofuran & $1,50 \mathrm{ab}$ & 36.200 & 6.651 a & 4.912 & 135 a & 294 \\
\hline Imidacloprid & $1,38 \mathrm{~cd}$ & 42.000 & $3.738 \mathrm{c}$ & 3.759 & $87 \mathrm{~b}$ & 252 \\
\hline Fipronil & 1,52 a & 40.600 & $3.668 \mathrm{c}$ & 4.320 & $104 \mathrm{~b}$ & 271 \\
\hline Testemunha & $1,40 \mathrm{bc}$ & 37.800 & $3.714 \quad \mathrm{c}$ & 3.873 & $100 \mathrm{~b}$ & 260 \\
\hline Média & 1,41 & 40.080 & 4.552 & 4.245 & 105 & 270 \\
\hline C.V.(\%) & 4 & 10 & 10 & 14 & 12 & 9 \\
\hline
\end{tabular}

Médias seguidas pela mesma letra na coluna, não diferem pelo teste de Tukey a $5 \%$; $\left({ }^{1}\right)$ Massa seca da parte aérea das plantas sem espigas; ns $=$ não significativo pelo teste $\mathrm{F}$ a $5 \%$.

O efeito dos tratamentos na produtividade de grãos, no experimento $\mathbf{A}$, não foi coerente com seu efeito sobre a massa de grãos por espiga, o que pode ser explicado, entre outros fatores, pelas acentuadas diferenças na população de plantas entre os tratamentos. Geralmente, para um mesmo potencial produtivo, quanto maior o número de plantas, menor a massa de grãos de cada espiga. Assim, o tratamentocom imidacloprid + carbofuran apresentou, ao mesmo tempo, maior população de plantas e menor massa de grãos por espiga, ao contrário do tratamento com fipronil (Tabela 5). Ressalte-se que o número de espigas por planta é variável e algumas espigas podem ser chochas, dificultando as extrapolações dessa inferência.

Algumas inferências do efeito dos tratamentos sobre o desenvolvimento das plantas não foram as mesmas nos estádios iniciais da cultura e por ocasião da colheita.

As avaliações das plantas raquíticas e da população inicial de plantas foram pouco esclarecedoras, ocorrendo discrepâncias com a avaliação final no experimento $\mathrm{A}$, provavelmente devido ao erro experimental, e redução acentuada da população de plantas até o fim do ciclo em todos os tratamentos, no experimento $\mathrm{B}$.

De maneira geral, considerando-se as duas áreas experimentais (A e B), a aplicação dos inseticidas fipronil e carbofuran proporcionou menor número de indivíduos de pragas de solo, sendo o carbofuran específico para percevejo-castanho, destacando-se também quanto à produtividade de palha e aos parâmetros de espiga. 
O thiamethoxam, especificamente em área com alta infestação de percevejos-castanhos e larvas de corós (experimento A), obteve valores intermediários para o número de indivíduos de percevejo-castanho e destacou-se quanto à produtividade de grãos e aos parâmetros de espigas.

Ao comparar os inseticidas, deve-se considerar ainda a relação entre o benefício do controle das pragas, avaliado pelo aumento da produtividade versus o valor de venda do milho, e o custo de cada produto. Os valores médios de aumento de produtividade com a aplicação dos inseticidas foram $28 \%$ e $12 \%$ para as áreas A e B respectivamente. Por ocasião da realização deste trabalho, verificou-se que os inseticidas avaliados apresentavam grande diferença de custo por unidade de área tratada.

\section{CONCLUSÕES}

1. Os inseticidas fipronil e carbofuran destacaram-se no controle do percevejo-castanho $S$. castanea; o fipronil destacou-se também no controle do coró Phyllophaga spp.

2. Os inseticidas carbofuran e thiodicarb reduziram o número de plantas danificadas por $S$. frugiperda.

3. Os inseticidas fipronil e thiamethoxam sobressaíram quanto aos parâmetros agronômicos na colheita do milho em área com alta infestação de percevejos-castanhos e larvas de corós. O inseticida carbofuran destacou-se na área com predominância de percevejos-castanhos, mas sem aumento da produtividade de grãos em relação à testemunha.

\section{AGRADECIMENTOS}

Aos produtores Sidiney Néspoli Andrade, Centirlei Néspoli Andrade e Odail Daví Vasques, pela cessão das áreas, ao departamento técnico da Coopermota pelo acompanhamento e facilidades oferecidas para desenvolver os experimentos e à empresa Aventis Crop Science, atualmente Bayer Crop Science, pelo financiamento parcial do projeto.

\section{REFERÊNCIAS BIBLIOGRÁFICAS}

ÁVILA, C.J.; GOMES, S.A. Controle químico do percevejocastanho Atarsocoris brachiariae (Hem.: Cydnidae) na cultura do milho. In: REUNIÃO SUL BRASILEIRA SOBRE PRAGAS DE SOLO, 8., 2001, Londrina. Resumos... Londrina: Embrapa Soja, 2001. p.232-235.
ÁVILA, C.J.; RUMIATTO, M. Controle químico-cultural do "coró" Liogenys sp. (Coleoptera: Scarabaeidae), em trigo (Triticum aestivum L.). In: CONGRESSO BRASILEIRO DE ENTOMOLOGIA, 16., Salvador. Resumos... Salvador: Sociedade Entomológica do Brasil, 1997. p.309.

BECKER, M. Estudos sobre a subfamília Scaptocorinae na região Neotropical (Hemiptera: Cydnidae). Arquivos de Zoologi, São Paulo, v.15, p.291-325, 1967.

BELLETTINI, S.; BELLETTINI, N.M.T.; FUKUSHIMA, E.H.; SILVA, W.G.; MANHOLER, C.T. Diferentes inseticidas em tratamento de sementes no controle da lagarta-do-cartucho do milho Spodoptera frugiperda (J.E. Smith, 1797). In: CONGRESSO NACIONAL DE MILHO E SORGO, 24., Florianópolis, 2002. Resumos... Sete Lagoas: ABMS, 2002. p.135.

CORSO, I.; OLIVEIRA, L.J.; FRIEDRICH, R. Efeito de inseticidas pulverizados no sulco de semeadura e misturados às sementes de soja sobre percevejo castanho da raiz em Cândido Mota, SP. In: WORKSHOP SOBRE PERCEVEJO CASTANHO DA RAIZ, 1., 1999, Londrina. Ata e resumos... Londrina: Embrapa Soja, 1999. p.56-58.

CRUZ, I. Efeito do tratamento de sementes de milho com inseticidas sobre o rendimento de grãos. Anais da Sociedade Entomológica do Brasil, Londrina, v.25, n.2, p.181-189, 1996.

CRUZ, I.; BIANCO, R. Manejo de Pragas na Cultura do Milho Safrinha. In: SEMINÁRIO NACIONAL DE MILHO SAFRINHA, 6., 2001, Londrina. Anais... Londrina: IAPAR, 2001. p.79-112.

CRUZ, I.; TURPIN, F.T. Efeito da Spodoptera frugiperda em diferentes estádios de crescimento da cultura do milho. Pesquisa Agropecuária Brasileira, Brasília, v.17, n.3, p.355-359, 1982.

CRUZ, I.; VIANA, P. A.; WAQUIL, J.M. Manejo das pragas iniciais de milho mediante o tratamento de sementes com inseticidas sistêmicos. Sete Lagoas: EMBRAPA-CNPMS, 1999. 39p. (EMBRAPA-CNPMS. Circular Técnica 31).

DUARTE, A.P. Milho: como fazer uma boa segunda safra. Cultivar, Pelotas, n.5, p.10-18, 2001.

GASSEN, D.N. Novos problemas com pragas na cultura do milho safrinha. In: SEMINÁRIO SOBRE A CULTURA DO MILHO SAFRINHA, 5, Barretos, 1999. Anais... Campinas: Instituto Agronômico, 1999. p.51-76.

GASSEN, D.N. Manejo de pragas associadas à cultura do milho. Passo Fundo: Aldeia Norte, 1996. 127p.

HABE, M.H.; OLIVEIRA, A.L.F.; GOLDFELD, A.B.F. Controle químico do bicho-bolo Liogenys sp. (Coleoptera: Scarabaeidea) através do tratamento de sementes na cultura do milho. In: REUNIÃO SUL BRASILEIRA SOBRE PRAGAS DE SOLO, 8., 2001, Londrina. Resumos... Londrina: Embrapa Soja, 2001. p.178-182.

MARTINS, J.P.P.; TANIGAWA, R.T.; ATARASSI, R.K.; NAKANO, O. Eficiência de diferentes inseticidas no controle de Phyllophaga sp., na cultura do milho. In: REUNIÃO SUL BRASILEIRA SOBRE PRAGAS DE SOLO, 7, 1999, Piracicaba. Resumos... Piracicaba: FEALQ, 1999. p.123. 
MEDEIROS, M.O.;SALES JUNIOR, O. Influence of precipitation volume and soil temperture on the population dynamics of the burrowing bug Atarsocoris brachiariae (Hemiptera: Cydnidae). In: INTERNATIONAL CONGRESS OF ENTOMOLOGY, 21., Foz do Iguaçu, 2000. Abstracts... Foz do Iguaçu: Embrapa Soja, 2000. v.1, p.268.

MORÓN, M.A. El genero Phyllophaga en Mexico. 1.ed., México: Instituto de Ecologia, 1986. 341p.

NAKANO, O.; FLORIM, A.C.P. Ensaio visando o controle do percevejo castanho com alguns inseticidas. In: WORKSHOP SOBRE PERCEVEJO CASTANHO DA RAIZ, 1., 1999, Londrina. Ata e resumos... Londrina: Embrapa Soja, 1999. p.54.

OLIVEIRA, L.J.; DE ANGELIS, S.; CORSO, I.C. et al. Efeito de diversos inseticidas sobre a população de percevejo castanho da raiz, em soja, Sapezal, MT. In: WORKSHOP SOBRE PERCEVEJO CASTANHO DA RAIZ, 1., 1999, Londrina. Ata e resumos... Londrina: Embrapa Soja, 1999. p. 60-61.

OLIVEIRA, L.J.; SANTOS, B.; PARRA, J.R. et al. Ciclo biológico de Phyllophaga cuyabana (Moser) (Scarabaeidae: Melolonthinae). Anais da Sociedade Entomológica do Brasil, Londrina, v.25, n.3, p. 431-437, 1996.

RAGA, A.; SILOTO, R.C. Resultados de pesquisa de controle químico do percevejo castanho Scaptocoris castanea em cultura de milho safrinha no Estado de São Paulo. In: WORKSHOP SOBRE PERCEVEJO CASTANHO DA RAIZ, 1., 1999, Londrina. Ata e resumos... Londrina: Embrapa Soja, 1999. p.55.

RAGA, A.; SILOTO, R.C.; SATO, M.E. Efeito de inseticidas sobre o percevejo castanho Scaptocoris castanea (Hem.: Cydnidae) na cultura algodoeira. Arquivos do Instituto Biológico, São Paulo, v.67, n.1, p.93-97, 2000.

RAMIRO, Z.A.; SOUZA FILHO, M.F.; RAGA, A. Plantas daninhas associadas ao percevejo castanho Scaptocoris castanea em cultura de soja. In: REUNIÃO DE PESQUISA DE SOJA DA REGIÃO CENTRAL DO BRASIL, 19., 1997, Jaboticabal. Anais... Jaboticabal: FCAV, 1997. p.194.

SALVADORI, J.R. Eficiência de inseticidas aplicados na semente e no solo para o controle do coró Phyllophaga sp., em trigo. In: REUNIÃO SUL BRASILEIRA SOBRE PRAGAS DE SOLO, 6., 1997, Santa Maria. Resumos... Santa Maria: UFSM, 1997. p.111-112.
SALVADORI, J.R. Avaliação de inseticidas aplicados em tratamento de sementes para controle do coró-do-trigo (Phyllophaga triticophaga) em trigo, safra 2000. In: REUNIÃO SUL BRASILEIRA SOBRE PRAGAS DE SOLO, 8, 2001, Londrina. Resumos... Londrina: Embrapa Soja, 2001a. p.170-172.

SALVADORI, J.R. Avaliação de inseticidas aplicados no sulco de semeadura para controle do coró-do-trigo (Phyllophaga triticophaga) em trigo, safra 2000. In: REUNIÃO SUL BRASILEIRA SOBRE PRAGAS DE SOLO, 8, 2001, Londrina. Resumos... Londrina: Embrapa Soja, 2001b. p.176-178.

SILOTO, R.C.; RAGA, A. Percevejo castanho nas culturas de soja e milho safrinha (Scaptocoris castanea e Atasrsocoris brachiariae). In: REUNIÃO ITINERANTE DE FITOSSANIDADE DO INSTITUTO BIOLÓGICO, 1., 1998, Miguelópolis. Anais... Campinas: Centro Experimental do Instituto Biológico,1998. p.79-84.

SILOTO, R.C.; RAGA, A.; SATO, M.E. Incidência de Scaptocoris castanea (Perty, 1833) (Hemiptera: Cydnidae) em duas profundidades no solo, no Vale do Médio Paranapanema, SP. In: REUNIÃO SUL BRASILEIRA SOBRE PRAGAS DE SOLO, 8., 2001, Londrina. Resumos.. Londrina: Embrapa Soja, 2001. p.221-223.

SILOTO, R.C.; SATO, M.E.; RAGA, A. Efeito de inseticidas sobre percevejo castanho Scaptocoris castanea (Perty) (Hem.: Cydnidae) em cultura de milho-safrinha. Revista de Agricultura, Piracicaba, v.75, n.1, p.21-27, 2000.

VILLALOBOS, F.J. Bioecology and sustainable management of white grubs (Coleoptera: Melolonthidae) pest of corn in "El Cielo" Biosphere Reserve, Tamaulipas, México. In: MORÓN, M.A. e ARAGÓN, A. (Eds.). Avances el estudio de la diversidad, importancia y manejo de los coleópteros edafícolas americanos. Puebla de Zaragoza: Sociedade Mexicana de Entomologia e Benemérita Universidad Autónoma de Puebla, 1988. p.173-184. 